\title{
Copra oil: chemistry, production. An extensive review on Indian specifications and functional aspects.
}

\author{
G.V. Pavan Kumar, N.V.V.S.S. Lakshmi, Ch. Deena, \\ B. Bhavani, P. Rajendra Kumar
}

Koringa College of Pharmacy, Korangi, India

\section{Keywords: \\ Coconut \\ Copra \\ Oil \\ Chemistry \\ Application \\ Functional}

\section{Article history:}

Received 14.03.2018

Received in revised

form 02.06.2018

Accepted 29.06.2018

\section{Corresponding author:}

G.V. Pavan Kumar

E-mail:

drgvpawankumar@

gmail.com

DOI:

$10.24263 / 2310-1008-$

2018-6-1-6

\section{Abstract}

Introduction. This research attempts to scientifically review the Chemistry and therapeutic benefits of Coconut oil, also commonly known as Copra oil.

Materials and methods. Review is based on the modern scientific literature analysis.

Results and discussion. $\mathrm{VCO}$, the purest form of coconut oil is essentially colorless and free from rancidity. VCO differs from natural coconut oil in the process of extraction. While the latter is extracted by cold milling or cold compression of copra (another name for dried coconut kernels), the former is extracted from coconut milk obtained from fresh coconuts. Natural or mechanical means are used to obtain the oil. Heat may or may not be used for extraction. The oil is not subject to chemical refining, bleaching or de-odorizing. Further processes such as fermentation, and centrifugal separation, refrigeration, and enzyme action, enables the separation of the oil from water or moisture. In some cases, micro-expelling is used i.e. boiling the fresh coconut oil, followed by evaporating the water / moisture or by direct cold compression of fresh dried coconut meat. The aroma of the fresh coconut can vary from mild to intense depending on the method employed for oil extraction.

The total production of edible grade coconut oil in India is about 400000 tons. Rotaries and expellers are used for Coconut oil production in India by crushing the dry coconuts (known as copra) for recovery of oil. VCO mainly consists of medium chain triglycerides (MCT), which are resistant to peroxidation. They differ from animal fat which consists of long chain saturated fatty acids and is the one main risk factor for cardiac complication. Medium chain fatty acids (MCFA) differ from long chain fatty acids in that they actually help to protect against heart disease. MCFA have been reported to lower the risk of both atherosclerosis and heart disease.

Conclusion. A number of health benefits have been attributed to this oil. These include benefits in skin care, hair care, stress relief, weight loss and cholesterol level maintenance, immunomodulatory effects, cardiovascular uses, and more recently in Alzheimer's disease. Coconut oil has a long shelf life and is used in baking industries, processed foods, infant formulas, pharmaceuticals, cosmetics and as hair oil. 


\section{Introduction}

Coconut is a plant in the Palmae family. For thousands of years tropical countries have used coconut from the tree (Cocos nucifera Linn), Family Aracaceae (palm family) as an integral part of their diet and livelihood. Known as "kalpa vriksha", in Sanskrit, this interprets as the palm which supplies all the necessities of life.In Indian traditional medicine, the coconut has been used as a medicinal plant for centuries. Coconut milk helps solve urinary problems, gallstones, and hematemesis. Coconut oil has been used as a burn wound remedy [1]. Coconut oil or Copra oil is an edible oil extracted from the kernel of mature coconuts of the coconut palm.Coconut oil also appears to promote the immune system response. Feeding coconut oil completely abolishes the expected immune factor responses to endotoxin and diminishes the production of proinflammatory cytokines in vivo [2, 3]. Recently, the biological properties of virgin coconut oil (VCO) have been widely investigated. It has been found that lauric acid is an effective compound in VCO. Lauric acid is the precursor of monolaurin [4], which has been shown to modulate immune cell proliferation [5] and possess antimicrobial activity [6]. Inflammation involves many other processes of the immune system; for example, during both acute and chronic inflammatory response, the immunological component cells are activated in response to foreign organisms or antigenic substances [7]. Recent studies point to the important role of inflammation in a wide variety of human diseases that are not primarily disorders of the immune system. These include cancer, atherosclerosis, ischemic heart disease, and some neurodegenerative diseases such as Alzheimer's disease [8-14].All parts of the coconut palm are useful, with significant economic value.

\section{Specification for coconut oil}

Indian-Standard IS: 6220-1971 specifies the quality parameters of copra for grading for different uses in India. This standard prescribes the methods of grading and the requirements of copra for extraction of oil and for table use, together with methods of sampling and test. The 3 types of copra are defined: type 1 (grades 1, 2 and 3), ball copra for table purpose; type 2 (grades 1 and 2), cup copra for table purpose; and type 3 (grades 1, 2 and 3), milling copra for oil extraction. The material shall be the kernels obtained from the fruits of Cocos nucifera Linn. Requirements cover physical and chemical properties, packing, marking, sampling and test.

\section{Chemistry and properties}

In the 1920s and 1930s it was discovered that coconut oil differed from other fats and oils in that it was found to be composed predominantly medium chain triglycerides. The composition of Fatty acids in VCO as determined by Gas Liquid Chromatography include Saturated fats: Lauric acid (45\% to 52\%), Myristic acid (16\% to 21\%), Palmitic acid (7\% to $10 \%$ ), Caprylic acid (5\% to $10 \%$ ), Capric acid ( $4 \%$ to $8 \%$ ), Stearic acid (2\% to $4 \%$ ), Caproic acid $(0.5 \%$ to $1 \%)$ and Palmitoleic acid (in traces) and Unsaturated fats: Oleic acid $(5 \%$ to $8 \%$ ), Linoleic acid (1\% to $3 \%$ ) and Linolenic acid (up to $0.2 \%$ ). VCO is colourless, free of rancidity and has a specific fresh natural coconut aroma and the specifications which should meet by the Virgin Coconut Oil listed in the Table 1. 

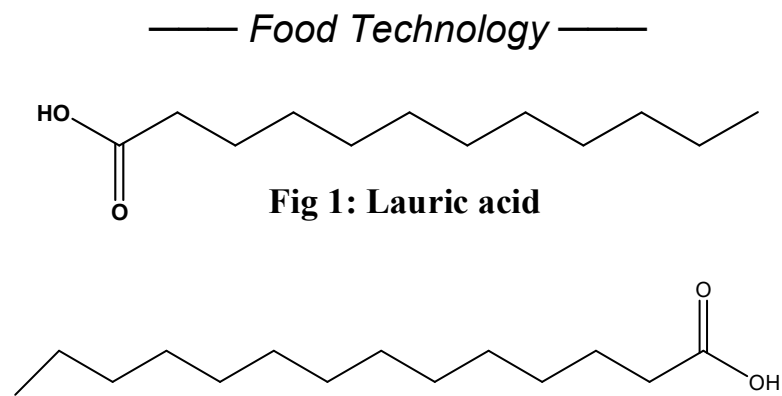

Fig 2: Myristic acid

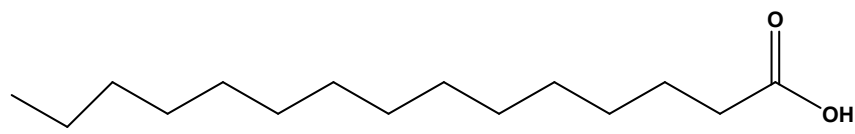

Fig 3: Palmitic acid<smiles>CCCCCCCC(=O)O</smiles>

Fig 4: Caprylic acid<smiles>CCCCCCCCCC(=O)O</smiles>

Fig 5: Capric acid<smiles>CCCCCC(=O)O</smiles>

Fig 7: Caproic acid<smiles>CCCCCCCC/C=C/CCCCCCC(=O)O</smiles>

Fig 7: Pamitoleic acid<smiles>CCCCCCCC/C=C/CCCCCCCC(=O)O</smiles> 


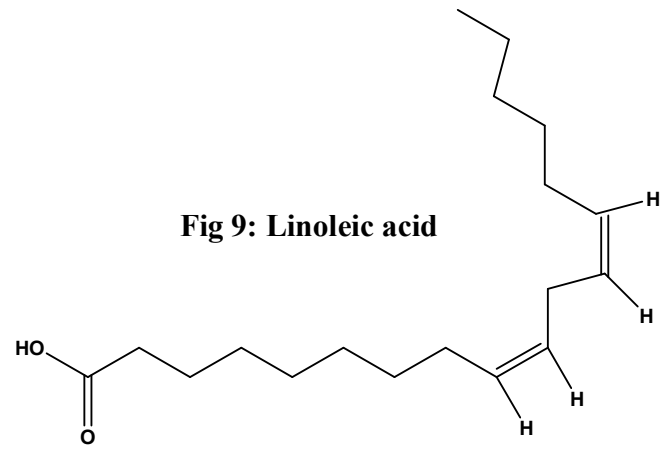

Table-1 Indian specification for coconut oil

Table 1

\begin{tabular}{|c|c|c|c|c|c|c|c|}
\hline & \multicolumn{4}{|c|}{ Expressed } & \multicolumn{3}{|c|}{ Solvent Extracted } \\
\hline Characteristics & $\begin{array}{l}\text { Refined } \\
\text { Grade }\end{array}$ & $\begin{array}{c}\text { Grade 1A } \\
\text { (Raw) }\end{array}$ & $\begin{array}{c}\text { Grade 1B } \\
\text { (Raw) }\end{array}$ & $\begin{array}{c}\text { Grade } 2 \\
\text { (Raw) }\end{array}$ & $\begin{array}{l}\text { Refined } \\
\text { Grade }\end{array}$ & $\begin{array}{c}\text { Semi } \\
\text { Refined }\end{array}$ & $\begin{array}{c}\text { Grade 1 } \\
\text { (Raw) }\end{array}$ \\
\hline $\begin{array}{l}\text { Moisture \& } \\
\text { insoluble } \\
\text { impurities } \\
(\max )(\%) \\
\end{array}$ & 0.1 & 0.25 & 0.25 & 0.25 & 0.1 & 0.25 & 1.0 \\
\hline $\begin{array}{l}\text { Colour } \\
\text { Lovibond } \\
\text { colour scale in } \\
\text { Y+5R } \\
\end{array}$ & 2 & 4 & 11 & 30 & 2 & 10 & 30 \\
\hline $\begin{array}{l}\text { Refractive } \\
\text { index at } 40^{\circ} \mathrm{C}\end{array}$ & $\begin{array}{c}1.4480- \\
1.4490\end{array}$ & $\begin{array}{c}1.4480- \\
1.4490\end{array}$ & $\begin{array}{c}1.4480- \\
1.4490\end{array}$ & $\begin{array}{c}1.4480- \\
1.4490\end{array}$ & $\begin{array}{c}1.4480- \\
1.4490\end{array}$ & $\begin{array}{c}1.4480 \\
- \\
1.4490\end{array}$ & $\begin{array}{c}1.4480- \\
1.4490\end{array}$ \\
\hline $\begin{array}{l}\text { Specific gravity } \\
\text { at } 30^{\circ} \mathrm{C} / 30^{\circ} \mathrm{C}\end{array}$ & $\begin{array}{c}0.915- \\
0.920\end{array}$ & $\begin{array}{c}0.915- \\
0.920\end{array}$ & $\begin{array}{c}0.915- \\
0.920\end{array}$ & $\begin{array}{c}0.915- \\
0.920\end{array}$ & $\begin{array}{c}0.915- \\
0.920\end{array}$ & $\begin{array}{c}0.915- \\
0.920\end{array}$ & $\begin{array}{c}0.915- \\
0.920\end{array}$ \\
\hline $\begin{array}{l}\text { Saponification } \\
\text { value (min) }\end{array}$ & 250 & 250 & 250 & 250 & 250 & 250 & 250 \\
\hline $\begin{array}{l}\text { Iodine value } \\
\text { (wijs) }\end{array}$ & $7.5-10$ & $7.5-10$ & $7.5-10$ & $7.5-10$ & $7.5-10$ & $7.5-10$ & $8.0-13$ \\
\hline $\begin{array}{l}\text { Acid value } \\
(\max )\end{array}$ & 0.5 & 2.0 & 6.0 & 8.0 & 0.5 & 1.0 & 10 \\
\hline $\begin{array}{l}\text { Unsaponifiable } \\
\text { (max) }\end{array}$ & 0.5 & 0.8 & 0.8 & 0.8 & 0.5 & 0.8 & 1.0 \\
\hline $\begin{array}{l}\text { Polenske value } \\
\text { (min) }\end{array}$ & 13.0 & 13.0 & 13.0 & - & 13.0 & - & - \\
\hline $\begin{array}{l}\text { Flash point, }{ }^{\circ} \mathbf{C} \\
\text { (min) }\end{array}$ & - & - & - & - & 225 & 100 & 90 \\
\hline
\end{tabular}




\section{Materials and methods}

Review is based on the analysis of scientific literature.

\section{Results and discussion}

\section{Common methods of production of coconut oil}

Different types of coconut oil for edible purposes are available viz, virgin coconut oil from wet coconuts (unrefined grade); coconut oil from dry coconuts (unrefined grade); and coconut oil by solvent extraction method (refined from coconut expeller cake). Virgin coconut oil is claimed to have more health benefits compared to coconut oil extracted from copra.

\section{Copra milling by traditional methods}

The extraction of oil from copra is one of the oldest seed crushing operations. In India and Sri Lanka copra is still crushed for oil extraction in the primitive chekkus as well as in rotary ghanis, expellers and hydraulic presses. The chekku is a fixed wooden or stone mortar inside which revolves on a hard wooden pestle. The pestle is attached to a long pole which is moved round via bullocks, donkey or by human labor. About $20-40 \mathrm{~kg}$ of copra can be handled by a chekku.

\section{Copra processing by continuous pressing}

This is done with the help of expellers. The oil expeller is essentially a mechanical screw press in which the oil is expelled from the copra by the pressure exerted by a continuous rotating warm shaft in the barrel or cage of the press. The barrel is built with openings to allow the escape of oil and these can be adjusted according to the type of seed being crushed.

\section{Hydraulic presses}

These are used in the large installations. They are of two main types-open or AngloAmerican presses and the closed or cage type presses. In this the space between the plates above ram and the head is divided by plates between which copra is put wrapped in press clothes. The common method is to extract oil from copra or the dry coconuts. Conventionally coconut oil is produced by expelling dry copra, followed by refining during which oil is exposed to high temperature. The copra based refined coconut oil or the solvent extracted and refined coconut oil will have a bland taste due to the refining processes.

\section{Wet coconut processing}

The wet coconuts are subjected to pressing to ooze the oil out along with coconut milk. This is processed afterwards without employing heat, shear, chemicals, refining and is known as virgin coconut oil. Virgin coconut oil has applications in pharmaceuticals and cosmetics. It is colorless with characteristic coconut flavor and finds several applications in medicinal, cosmetics and cooking purposes. Traditionally, virgin coconut oil is produced by fermentation method, where coconut milk expelled from freshly harvested coconuts is fermented for 24-36 hr, and during this period, the oil phase gets separated from aqueous phase. Further, the resulting wet oil is slightly heated for a short time to remove the moisture and finally filtered. The main disadvantages of this process are low oil recovery and fermented odor, which masks the characteristic coconut flavor of the oil. 


\section{Physico-chemical characteristics of coconut oil}

\section{Solubility}

Coconut oil is insoluble in water. At temperature above its melting point it is completely miscible with most of the non-hydroxylic solvents such as light petroleum, benzene, carbon tetrachloride etc. In alcohol,coconut oil is more soluble than most common fats and oils.

\section{Chemical composition}

Coconut oil contains a high proportion of glycerides of lower chain fatty acids. The oil is highly stable towards atmospheric oxidation. The oil is characterized by a low iodine value high saponification value, high saturated fatty acids content and is a liquid at room temperatures of $27^{\circ} \mathrm{C}$.

Table 2

Physico-chemical Characteristics of coconut oil

\begin{tabular}{|l|c|c|c|}
\hline \multicolumn{1}{|c|}{$\begin{array}{c}\text { Appearance } \\
\text { Odour }\end{array}$} & $\begin{array}{c}\text { Virgin coconut oil } \\
\text { from wet coconut }\end{array}$ & $\begin{array}{c}\text { Unrefined } \\
\text { coconut Oil from } \\
\text { copra }\end{array}$ & $\begin{array}{c}\text { Refined } \\
\text { coconut oil }\end{array}$ \\
$\begin{array}{l}\text { Colorless } \\
\text { Coconut smell }\end{array}$ & $\begin{array}{c}\text { Slight brownish } \\
\text { Coconut smell }\end{array}$ & $\begin{array}{c}\text { Colourless } \\
\text { Odourless }\end{array}$ \\
\hline Melting point ${ }^{\circ}$ C & 24 & 24 & 24 \\
\hline Moisture (\%) & $<0.1$ & $<0.1$ & $<0.1$ \\
\hline Iodine value (cg I2/g) & $12-15$ & $12-15$ & $10-12$ \\
\hline $\begin{array}{l}\text { Peroxide value (meq. } \\
\text { O2/kg) }\end{array}$ & $0-1$ & $0-1$ & $0-1$ \\
\hline $\begin{array}{l}\text { Saponification value(mg } \\
\text { KOH/g) }\end{array}$ & $245-255$ & $245-255$ & $250-255$ \\
\hline Phospholipids(\%) & 0.1 & 0.1 & 0.0 \\
\hline $\begin{array}{l}\text { Unsaponifiable } \\
\text { matter(\%) }\end{array}$ & - & $0.42 \%$ & $0.19 \%$ \\
\hline Tocopherols mg/kg & $150-200$ & $150-200$ & $4-100$ \\
\hline Phytosterols mg/kg & - & $400-1200$ & - \\
\hline Total phenolics mg/Kg & 640 & 618 & 20 \\
\hline $\begin{array}{l}\text { Fatty acid } \\
\text { composition(relative\%) }\end{array}$ & - & - & - \\
\hline Saturates & 92.0 & 92.0 & 92.0 \\
\hline Monounsaturates & 6.0 & 6.0 & 6.0 \\
\hline Polyunsaturates & 2.0 & 2.0 & 2.0 \\
\hline
\end{tabular}

\section{Unsaponifiable matter}

All natural fats contain minor quantities of substance other than fatty acid glycerides. The unsaponified constituent is mostly sterols. The unsaponifiable constituent of coconut oil include a small amount of tocopherols and phytosterols. 


\section{Chemistry of fatty acids and triglycerides}

\section{Medium chain triglycerides}

MCTs are a class of lipids in which three saturated fats are bound to a glycerol backbone. What distinguishes MCTs from other triglycerides is the fact that each fat molecule is between six and twelve carbons in length [16]. MCTs are a component of many foods, with coconut and palm oils being the dietary sources with the highest concentration of MCTs. MCTs are also available as a dietary supplement [17]. MCTs have a different pattern of absorption and utilization than longchain triglycerides (LCTs) that make up 97 percent of dietary fats. For absorption of LCTs to occur, the fatty acid chains must be separated from the glycerol backbone by the lipase enzyme. These fatty acids form micelles, are then absorbed and reattached to glycerol, and the resultant triglycerides travel through the lymphatics en route to the bloodstream. Up to 30 percent of MCTs are absorbed intact across the intestinal barrier and directly enter the portal vein. This allows for much quicker absorption and utilization of MCTs compared to LCTs. MCTs are transported into the mitochondria independent of the carnitine shuttle, which is necessary for LCT mitochondrial absorption. Oxidation of MCTs provides 8.3 calories per gram, while LCTs provides 9.2 calories per gram [18].

\section{Nutritional effects of coconut oil blends}

Bellenand et al [19] studied the effects of coconut oil on heart lipids and on fatty acid utilization in rapeseed oil. The cardiac lipidosis was proportional to the content of erucic acid in the diet. At 60 days, the high level of 22:6 in the cardiac phospholipids of rats fed rapeseed oil was reduced by the addition of sunflower oil but not by coconut oil. Thus, the blending of rapeseed oil with coconut oil apparently is less desirable than that of rapeseed oil and sunflower oil. McCutcheon et al[20] studied the cardiopathogenicity of rapeseed oils and oil blends differing in erucic, linoleic and linolenic acid content on male Wistar rats using semipurified diets. Lowest lesion incidence was obtained with safflower oil and hydrogenated coconut oil. It has been postulated that linolenic acid plays a role in the etiology of cardiac necrosis observed when rats are fed diets containing low erucic acid rapeseed oils.

Theuer [21] developed fat compositions for infant formulas containing vegetable fats with a fatty acid simulating that of human milk. Grandadam [22] developed processes to recover the proteins of the coconut from copra cake, or directly from fresh coconut meat by different processes. The improved Itipat process of double pressing allows recovery of $93.45 \%$ of the oil and $91.9 \%$. Aliwalas [23] studied the following process for oil extraction from coconut meat: (i) wet method(using a De Laval centrifuge), (ii) hydraulic pressing, (iii) pressing plus solvent extraction, (iv) filtration extraction (direct solvent extraction). Oil extraction efficiencies obtained were: (i) $79.56 \%$ (increased to $96.3 \%$ by subsequent solvent extraction), (ii) $76.47 \%$, (iii) $99.65 \%$, (iv) 96.58 . Protein contents of isolates from (i) ranged from 59 to $75 \%$. Protein efficiency ratio (PER) biological value (BV), true digestibility (TD) and net protein utilization (NPU) of coconut flour from (ii), (iii) and (iv) were: PER 2.42, 2.55, 2.42; BV 77,84, 79; TD 76, 74, 72; NPU 68, 64, 66. Values for coconut isolate prepared by heat coagulation of cream or aqueous portion of fresh coconut milk from (i) were: PER 1.50, 2.20; BV 72, 80; TD 88, 92; NPU 59, 65. The traditional rural method gave an oil extraction efficiency of 82.45, and a protein isolate with PER 1.25, BV 62, TD 86 and NPU 58. Reena Rao and Lokesh [24,25], Anitha Nagaraju and Lokesh [26,27] and Reena and Lokesh [28] have used immobilized lipase systems for the synthesis of structured lipids from coconut oil and omega 6 and omega 3 fatty acids and carried out nutritional evaluation of the 
same in rats. They found beneficial effects in the lipid profile after enzymatic acidolysis of coconut oil with omega 6 and omega 3 fatty acids.

\section{Clinical Applications}

Virgin coconut oil (VCO) has been consumed worldwide for various health-related reasons and some of its benefits have been scientifically evaluated.

\section{Antioxidant and Antistress Activity}

A study carried out by Yeap SK et al evaluated the antistress and antioxidant effects of virgin coconut oil in vivo. VCO reduced lipid peroxidation and increase the activity of SOD in the serum of mice undergoing the forced swim test and the brains of mice subjected to chronic cold restraint[29]. VCO has been reported to be rich in polyphenols and these contribute to the increased antioxidant enzyme levels, which in turn reduces inflammation and lipid peroxidation in VCO-treated mice. Restoration of brain antioxidant levels hinders further neuronal damage thereby preventing subsequent monoamine depletion[30]. The potential of VCO to prevent exercise- and chronic cold restraint stress-induced damage and to restore the antioxidant balance was demonstrated and this was attributed to the polyphenols and medium-chain fatty acids present in VCO. In another study on the comparative effect of VCO with copra oil, olive oil and sunflower oil on endogenous antioxidant status and paraoxonase-1 activity in ameliorating the oxidative stress in rats, findings revealed that dietary VCO improved the antioxidant status as compared to the other three oil- fed groups, as was evident from increased catalase, superoxide dismutase, glutathione peroxidase and glutathione reductase activities in tissues[31].

\section{Hepatoprotective activity}

Several studies have reported the antioxidant activity of VCO. Oxidative stress induced by the generated free radicals plays a lead role in the development of hepatic toxicity[32]. A study was conducted on hepatoprotective activity of VCO on 2, 4-Dichlorophenoxyacetic acid $(2,4-\mathrm{D})$ induced liver damage in rats[33]. Rats treated with 2, 4-D showed a significant liver damage with increased serum transaminases and alkaline phosphatase enzymes activities, hepatic lipid peroxidation and liver free fatty acids. Serum total protein, albumin, hepatic superoxide dismutase and glutathione peroxidase enzymes activities were significantly reduced. Inflammation and necrosis were observed in liver sections of treated rats. VCO oil treated animals showed an improvement in hepatic antioxidant enzymes, serum transaminases activities and liver free fatty acids levels which was confirmed by histopathological examination, thereby establishing the hepato protective activity of $\mathrm{VCO}[34]$.

\section{Anti-inflammatory, analgesic, and antipyretic activities of VCO}

A study conducted by Intahphuak et $a l$, evaluated the anti-inflammatory, analgesic, and antipyretic effects of VCO in rats using ethyl phenyl propiolate-induced ear edema and carrageenan and arachidonic acid-induced paw edema. VCO was found to possess moderate anti-inflammatory effects.Through reduction of the transudative weight, granuloma formation, and serum alkaline phosphatase activity, VCO exhibited an inhibitory effect on chronic inflammation. In acetic acid-induced writhing, the model for analgesic activity and 
for yeast-induced hyperthermia for antipyretic activity, VCO showed a moderate analgesic and antipyretic effect[35].

\section{Wound Healing Effect}

Wound healing is a complex process where the skin or other body tissue repairs itself after injury. The oil of Cocos nucifera has been reported to be an effective wound healing agent[36]. Nevin et al studied the effect of topical application of virgin coconut oil on skin components and antioxidant status during dermal wound healing in young rats. In their study, animals were treated for 10 days with VCO, 24 hours after creation of the wound. VCO's healing activity was evaluated by monitoring time for complete epithelization in addition to various parameters of the wound's granulation tissue. Solubility pattern of collagen, glycohydrolase activity and granulation tissue histopathology were also studied. Animals treated with VCO showed much faster wound healing activity, indicated by a decreased time in complete epithelization and higher levels of various skin components. The significant increase of Pepsin-soluble collagen and glycohydrolase activities observed indicated higher collagen cross- linking and its turnover. They concluded that the wound healing activity of VCO may be a cumulative effect of various minor biologically active components present within [37].

\section{Effect on Dermatitis}

Atopic dermatitis (AD) is a chronic skin disease characterized by features of defective epidermal barrier function and inflamed cutaneous layer. In this condition trans epidermal water loss (TEWL) is increased and the ability of the stratum corneum to hold water is impaired. This leads to decreased skin capacitance and hydration. A study by Evangelista et al investigated the topical effect of VCO on SCORAD index, trans epidermal water loss, and skin capacitance in mild to moderate pediatric atopic dermatitis using a randomized controlled trial design. A total of 117 patients included were evaluated at baseline, and then at 2, 4, and 8 weeks respectively. The results concluded the superiority of VCO over mineral oil among pediatric patients with mild to moderate AD [38].

\section{Use as an Ocular Rewetting Agent}

Dry eye is a symptom caused by the lack of quality /quantity of tears or defect on the ocular surface area. That leads a condition of discomfort, visual disturbance; tear film instability, increased osmolality of the tear film and inflammation of the ocular surface, which ameliorate the damage to the ocular surface. Among all the therapeutic option for dry eyes, artificial tears is the mainstay for the initial management of dry eye patient. Due to the complexity of tear film, it is difficult to manufacture tears that would be similar to that of the human eye. Several brands of artificial tears are commercially available, that would consist of Hydroxypropyl methyl cellulose, Poly vinyl alcohol, sodium hyaluronate and oil based tears. A previous study showed that liposomal spray applied on closed eye lid had increased the thickness of lipid layer and also significantly increased the tear film stability. On account of this study Dept. of Optometry and vision science at Malaysian University evaluated the usage of VCO as a supplement for tear film. A pilot study was carried out on the efficacy of $\mathrm{VCO}$ as an ocular rewetting agent on Rabbit eyes. VCO was found to be safe in the dry eye and its anti-inflammatory property was attributed to be responsible for its significant beneficial effect in the management of dry eyes[39]. 


\section{Effect on Alzheimer's disease}

In the neurological disorder Alzheimer's disease (AD), memory loss and cognitive decline occurs because of death of brain cells. The neurodegenerative disease starts as mild dementia getting progressively worse. In the brain, the lipid macromolecule, cholesterol is utilized as an antioxidant, for structural scaffolding of the neural network, as an electrical insulator (to prevent ion leakage), and as a functional membrane component. Cholesterol is utilized in the wrapping and synaptic delivery of the neurotransmitters and also plays an important role in the formation and functioning of synapses in the brain. Several studies[40] have proven the lack of cholesterol in the brains of AD patients. In contrast, a positive correlation (better memory function and reduced dementia) was observed between high cholesterol levels and longevity in a population above 85 years old. A study appearing in the American Journal of Cardiology in February 2011 suggested that a diet with adequate amounts of saturated fat is essential to maintain HDL high cholesterol levels. Those with deficiencies and suffering from neurological disorders needed to consider a diet that is high in saturated fat. The saturated fat of coconut oil provides the brain with an alternate source of energy in ketones. Ketones are high energy fuels that nourish the brain. Fasting/starvation can trigger the production of ketones. Ketones are also formed by the conversion of medium chain fatty acids in certain foods. Coconut oil is nature's richest source of these medium chain triglycerides (MCTs) [41]. A study done in 2004 took MCTs from coconut oil and put them into a drink that was given to Alzheimer's patients while a control group took a placebo. They observed significant increases in levels of the ketone body beta-hydroxybutyrate (betaOHB) 90 minutes after treatment. When cognitive tests were administered, higher ketone values were associated with greater improvement in paragraph recall with MCT treatment relative to placebo across all subjects [42].

\section{Effect on blood pressure elevation}

Hypertension or elevated blood pressure is the main risk factor for cardiovascular complications such as coronary heart disease, atherosclerosis, and stroke. Many studies to prevent the elevation of blood pressure have been carried out. Badlishah Sham Nurul-Iman et al carried out a study on Effect of VCO on prevention of blood pressure elevation and Improves Endothelial Functions in rats fed with repeatedly heated palm oil. This study explored the effects of virgin coconut oil (VCO) in male rats fed repeatedly with heated palm oil on blood pressure, plasma nitric oxide level, and vascular reactivity. In their study elevation of blood pressure was created by the repeated feeding of heated palm oil. On overheating, the free radicals that were generated induced oxidative stress within the blood vessel, affecting the NO level in the endothelial cells. In male rats, supplementation with repeatedly heated palm oil VCO was found to prevent blood pressure elevation and to also decrease nitric oxide deactivation. In addition, VCO did not influence relaxation but decreased vasoconstriction of the endothelium [43].

\section{Immunomodulatory effect}

In 1966, Jon Kabara discovered that Medium Chain Fatty Acids (MCFA's) of virgin coconut oil are incredible for antimicrobial properties that kill harmful viruses, bacteria, fungi, and parasites. When MCFA's are digested, they break down into free fatty acids and monoglycerides[44] .Lauric Acid, Capric acid, and Caprylic acid are the important medium chain fatty acids present in coconut oil that possess antimicrobial activity. Their 
monoglyceride form, monolaurin, monocaprylin, and monocaprin hinder microbes from terrorizing the immune system. Individually, these fatty acids act on microbes in different ways. Some may kill a particular organism that causes fungal infections but may not be as useful on other microbes. Unitedly, however they act as a highly powerful defence against diseases. Monolaurin (monoglyceride form of lauric acid) is considered to have the best antiviral, antifungal, and antibacterial effect[45]

\section{Effect on blood sugar control}

A study on Insulinotropic potency of lauric acid: a metabolic rationale for medium chain fatty acids (MCFA) in TPN formulation by Garfinkel M et al proved that the effect of MCFA on insulin secretion depends upon its chain length. Among all MCFA capric acid (C10) and lauric acid were observed to display the most potent effects on insulin secretion [46]. Another study proved that, as compared to other oils, coconut oil in the diet enhanced insulin action and improved binding affinity [47].

\section{Effect on weight loss}

A study conducted on the effect of dietary medium- and long-chain triacylglycerols (MLCT) on accumulation of body fat in healthy humans by Kasai $\mathrm{M}$ et al proved that a daily intake of MLCT diet could cause a reduction in body weight and body fat accumulation. Volunteers in a double-blind study for 12 weeks, consumed daily at breakfast, test bread, with $1.7 \mathrm{~g}$ MCFA, bread made with long-chain triacylglycerols (LCT) was consumed by the control group. A significant decrease of body weight and amount of fat, with a significant decrease in serum total cholesterol was observed in the test group [48]. In another study on the effect of dietary supplementation with coconut oil on the biochemical and anthropometric profiles of women with abdominal obesity (waist circumferences (WC) $>88 \mathrm{~cm}$ ) the intake of dietary supplement with VCO was observed to decrease the amount of abdominal fat [49].

\section{Healing properties of coconut oil}

Coconut oil is antiviral, antifungal (kills yeast too) and antibacterial. It attacks and kills viruses that have a lipid (fatty) coating, such as herpes, HIV, hepatitis C, the flu, and mononucleosis. It kills the bacteria that cause pneumonia, sore throats, dental cavities, urinary tract infections, meningitis, gonorrhea, food poisoning and many more bacterial infections [50]. It kills the fungus/yeast infections that cause candida, ringworm, athletes foot, thrush, jock itch and diaper rash.

\section{Conclusion}

Coconut oil is consumed in tropical countries for thousands of years. Studies done on native diets high in coconut oil consumption show that this population is generally in good health. Coconut oil has a long shelf life and is used in baking industries, processed foods, infant formulas, pharmaceuticals, cosmetics and as hair oil. The oil contains $92 \%$ of saturates consisting of medium chain fatty acids in the form of triglycerides, and about $8 \%$ of unsaturates consisting of oleic and linoleic acids as triglycerides. The oil has a small amount of unsaponifiable matter $(<0.5 \%)$, is colourless and has a odour typical of the coconuts. The oil has small amounts of tocopherols and tocotrienols and phytosterols. The oil is known to 
have antiviral and antibacterial effects and excellent healing properties. It gets easily absorbed in the body and is a nature mimic of the human breast milk fat and hence used in infant formulae. With all these good quality attributes, the side effects of the oil has also been reported especially in cardiovascular diseases due to the presence of less of unsaturated fatty acids in the triglycerides of the oil. It is hypothesized that due to lower amount of PUFA, there is a possibility of atherogenecity development during long term usage of the oil. However, more research is needed to clearly understand the many good effects of the oil.

\section{References}

1. Chaichit C. (2004), Thai Herbs and Herbal Products. Bangkok, Srimuang Printing Co., pp. $155-156$.

2. Wan J.M., Grimble R.F. (1987), Effect of dietary linoleate content on the metabolic response of rats to Escherichia coli endotoxin, Clin Sci, 72, pp. 383-385

3. Sadeghi S., Wallace F.A., Calder P.C. (1999), Dietary lipids modify the cytokine response to bacterial lipopolysaccharide in mice, Immunology, 96, pp. 404-410.

4. Pereira C.C., Da Silva M.A., Langone M.A. (2004), Enzymatic synthesis of monolaurin, Appl Biochem Biotechnol, 113-116, pp. 433-445.

5. Witcher K.J., Novick R.P., Schlievert P.M. (1996), Modulation of immune cell proliferation by glycerol monolaurate, Clin Diagn Lab Immunol, 3, pp. 10-13.

6. Bergsson G., Steingrímsson Ó., Thormar H. (2002), Bactericidal effects of fatty acids and monoglycerides on Helicobacter pylori, Int J Antimicrob Agents, 20, pp. 258-262.

7. Wagner W, Khanna P, Furst DE (2004), Nonsteroidal anti-inflammatory drugs, diseasemodifying antirheumatic drugs, nonopioid analgesics, and drugs used in gout. In, Katzung B.G., ed., Basic \& Clinical Pharmacology, 9th ed. Singapore, McGraw-Hill, pp. 576-603.

8. Kumar V., Abbas A.K., Fausto N. (2005), Acute and chronic inflammation. In, Kumar V., Abbas A.K., Fausto N., ed., Robbins and Cotran Pathologic Basis of Disease, 7th ed. Philadelphia, Elsevier Saunders, pp. 47-86.

9. Philippine National Standard for virgin coconut oil (VCO) Bureau of Product Standards (2004), Department of Trade and Industry, Philippine, PNS/BAFPS 22.

10. Marina A.M., Che Man Y.B., Amin I. (2009), Virgin coconut oil, emerging functional food oil, Trends Food Sci Technol, 20(10), pp. 481-487.

11. Marina A.M., Che Man Y.B., Nazimah A.H. (2009), Chemical properties of virgin coconut oil, J Am Oil Chem Soc, 86, pp. 301-307.

12. Bezard J., Bugaut M., Clement G. (1971), Triglyceride composition of coconut oil, $J$. Am. Oil Chem. Soc, 48(3), pp. 134-139.

13. Conrado S. Dayrit. (2003), Coconut oil, Atherogenic or Not? (What therefore causes Atherosclerosis?), Philipp J Cardiol, 31(3), pp. 97-104.

14. Import of vegetable oils, The Solvent Extractors' Association of India, Mumbai, India, Available at: $\mathrm{http} / / \mathrm{www}$.seaofindia.com.

15. (1968), Specification for coconut oil. Ceylon, Ceylon-Standard, CS 32, 1968 24pp. Bureau of Ceylon Standards.

16. Babayan V.K. Medium chain triglycerides. (1988), In dietary fat requirements in health and development. (CJ Beare-Rogers, ed), AOCS press, Champain, pp. 73-86.

17. Heydnger J.A., Nakhasi D. K. (1966), Medium chain Triacylglycerols, J. of Food Lipids, 3, pp. 251-257. 
18. Ralph Hoahland, George G. Snider, (1943), Digestability of certain higher saturated fatty acids and triglycerides, J. Nutri., 26(3), pp. 219-225.

19. Bellenand J.F., Baloutch G., Ong N., Lecerf J., (1980), Effects of coconut oil on heart lipids and on fatty acid utilization in rapeseed oil. Lipids, 15(11), pp. 938-943.

20. McCutcheon J.S., Umermura T., Bhatnagar M.K., Walker B.L., (1986), Cardiopathogenicity of rapeseed oils and oil blends differing in erucic, linoleic and linolenic acid content. Lipids, 11(7), pp. 545-552.

21. Theuer R.C. (1981), Fat compositions for infant formulas, US Patent 4, 282, 265.

22. Grandadam Y., (1973), The proteins of the coconut, Industries Alimentaires et Agricoles, 90(9/10), pp. 1253-1268.

23. Aliwalas A.R., Gonzales A.L., Claudio T.R., Benet R., (1969), A study of the wet and dry methods of extracting oil from coconut meat, Phillip. J. Sci., 98(2), pp. 139-149.

24. Reena Rao, (2001), Enzymatic synthesis of structured lipids by immobilized lipase systems in organic solvents. Ph.D. Thesis, CFTRI, University of Mysore, Mysore.

25. Reena Rao, Lokesh B.R., (2003), Nutritional evaluation of an omega 6 fatty acid containing structured lipid synthesized from coconut oil, Lipids, Mol. and Cell. Biochem., 248 (1-2), pp. 25-33.

26. Anitha Nagaraju, and B.R. Lokesh, (2007), Interesterified coconut oil blends with groundnut oil or olive oil exhibit greater hypocholesterolemic effects compared with their native physical blends in rats, Nutri. Res., 27, pp. 580-586.

27. Anitha Nagaraju, B.R. Lokesh, (2008), Rat fed blended oils containing coconut oil with groundnut oil or olive oil showed an enhanced activity of hepatic antioxidant enzymes and a reduction in LDL oxidation, Food Chem., 108 , pp. 950-957.

28. Malongil B. Reena, Belur R. Lokesh, (2007), Hypolipidemic effect of oils with balanced amounts of fatty acids obtained by blending and inter esterification of coconut oil with rice bran oil or sesame oil, J. Agric. Food Chem., 55, pp. 10461- 10469.

29. Nevin K.G., Rajamohan (2006), Virgin coconut oil supplemented diet increases the antioxidant status in rats, Food Chem, 99, pp. 260-266.

30. Arunima S., Rajamohan T. (2013), Effect of virgin coconut oil enriched diet on the antioxidant status and paraoxonase 1 activity in ameliorating the oxidative stress in rats - a comparative study, Food Funct. 4(9), pp. 1402-9.

31. Otuechere C.A., Madarikan G., Simisola T., Bankole O., Osho A. (2014), Virgin coconut oil protects against liver damage in albino rats challenged with the anti-folate combination, trimethoprim-sulfamethoxazole, J Basic Clin Physiol Pharmacol, 25(2), pp. 249-53.

32. Hanaa M. Abd E.F., Lamiaa A.A.B. (2013), Hepatoprotective Effect of Olive and Coconut oils against Oxidative Stress- Induced by 2, 4 Dichlorophenoxyacetic Acid, Indian J Appl Res , 3, 12, pp. 42-46.

33. Zakaria Z.A., Rofiee M.S., Somchit M.N., Zuraini A., Sulaiman L.K., The L.K., Salleh M.Z., Long K. (2011), Hepatoprotective activity of dried- and fermented-processed virgin coconut oil, Evid Based compl Alt Med , pp. 142739-48.

34. Intahphuak S, Khonsung P, Panthong (2010), A.Anti-inflammatory, analgesic, and antipyretic activities of virgin coconut oil, Pharm Biol , 48(2), pp. 151-7.

35. Burn wound healing property of Cocos nucifera (2008), An appraisal, Indian J Pharmacol, 40(4), pp. 144-146.

36. Nevin K.G., Rajamohan T. (2010), Effect of topical application of virgin coconut oil on skin components and antioxidant status during dermal wound healing in young rats, Skin Pharmacol Physiol, 23(6), pp. 290-7. 
37. Evangelista M.T., Abad-Casintahan F., Lopez-Villafuerte L. (2014), The effect of topical virgin coconut oil on SCORAD index, trans epidermal water loss, and skin capacitance in mild to moderate pediatric atopic dermatitis, a randomized, double-blind, clinical trial, Int J Dermatol, 53(1), pp. 100-8.

38. Haliza A.M., Sharanjeet K., Ahmad R.G., Ng. Chinn H., Nor H. S. (2014), The Efficacy of Virgin Coconut Oil as Ocular Rewetting Agent on Rabbit, Evid Based compl Alt Med , pp. 135987.

39. Seneff S., Glyn W., Luca M. Nutrition and Alzheimer's disease (2011), The detrimental role of a high carbohydrate diet, Eur J Intern Med, 22(2), pp. 134-40.

40. Rahilly T.C.R., Spiro A.,Vokonas P., Gaziano J.M. (2011), Relation between HighDensity Lipoprotein Cholesterol and Survival to Age 85 Years in Men, Am J Cardiol, 107(8), pp. 1173-7.

41. Reger MA, Henderson ST, Hale C, Cholerton B, Baker LD, Watson GS, Hyde K, Chapman D, Craft S. (2004), Effects of beta-hydroxybutyrate on cognition in memoryimpaired adults, Neurobiol Aging, 25, 3, pp. 311-4.

42. Badlishah S Nurul-Iman, Yusof Kamisah, Kamsiah Jaarin, Hj Mohd Saad Qodriyah (2013), Virgin Coconut Oil Prevents Blood Pressure Elevation and Improves Endothelial Functions in Rats Fed with Repeatedly Heated Palm Oil, Evid Based Compl Alt Med, (5), pp. 629329.

43. Ogbolu D.O., Oni A.A., Daini O.A., Oloko A.P. (2007), In vitro antimicrobial properties of coconut oil on Candida species in Ibadan, Nigeria, JMed Food, 10(2), pp. 384-7.

44. Shilling M., Matt L., Rubin E., Visitacion M.P., Haller N.A., Grey S.F., Woolverton C.J. (2013), Antimicrobial effects of virgin coconut oil and its medium-chain fatty acids on Clostridium difficile, J Med Food, 16(12), pp. 1079-85.

45. Garfinkel M., Lee S., Opara E.C., Akwari O.E. (1992), Insulinotropic potency of lauric acid, a metabolic rationale for medium chain fatty acids (MCF) in TPN formulation, $J$ Surg Res, 52(4), pp. 328-33.

46. Ginsberg B.H, Jabour J, Spector A.A. (1982), Effect of alterations in membrane lipid unsaturation on the properties of the insulin receptor of Ehrlich ascites cells, Biochim. Biophys. Acta, 690(2), pp.15.

47. Kasai M., Nosaka N., Maki H., Negishi S., Aoyama T., Nakamura M., et Al. (2003), Effect of dietary medium- and long-chain triacylglycerols (MLCT) on accumulation of body fat in healthy humans, Asia Pac J Clin Nutr, 12(2), pp. 151-60.

48. Assuncao ML, Ferreira HS, dos Santos AF, Cabral CR Jr, Florencio TM. (2008), Effects of dietary coconut oil on the biochemical and anthropometric profiles of women presenting abdominal obesity, Lipids., 44(7), pp. 593-601.

49. Kabara J.J. (2011), Health oils from the tree of life. Nutrition and health aspects of coconut oil.

50. Lim Sylianco C.Y. (1987), Anticarcinogenic effects of coconut oil, Phillip. J. Coconut Studies, 12(2), pp. 89-102. 